\title{
Pulmonary MALT Lymphoma in Patients with Sjögren's Syndrome
}

\author{
Ralph Yachoui, MD; Chady Leon, MD; Kajal Sitwala, MD and Mazen Kreidy, MD
}

To describe clinical features and outcomes of seven patients with pulmonary mucosa-associated lymphoid tissue (MALT) lymphoma in the setting of underlying primary Sjögren's syndrome from a single center, we reviewed medical records of consecutive patients with pulmonary MALT lymphoma evaluated at our facility from January I, 1999 to December 3I, 2015 for clinical features, laboratory, pathologic and radiographic findings, management, and outcomes. Out of 13 patients with pulmonary MALT lymphoma, 7 (54\%) met the criteria for Sjögren's syndrome. The mean age at lymphoma diagnosis was 66 years; male-female ratio was I:6. One-third of patients were asymptomatic at the time lymphoma was discovered. When symptomatic, patients reported nonspecific pulmonary complaints such as cough and dyspnea. All patients had positive antinuclear antibody and anti-SSA/Ro antibody. Rheumatoid factor was positive in six cases. A monoclonal gammopathy was present in three patients; the remaining four had polyclonal hypergammaglobulinemia. The radiologic, morphologic, and immunohistochemical features of primary Sjögren's syndrome-associated pulmonary MALT lymphomas did not differ significantly from pulmonary MALT lymphoma cases in general. All treatment modalities used resulted in complete and sustained response. One patient died II years after initial diagnosis with no lymphoma but of another cause. The remaining six patients are still alive and disease-free to date. The present series confirms the favorable course of pulmonary MALT lymphoma in Sjögren's patients. The overall imaging and pathologic features are in accordance with pulmonary MALT lymphoma not associated with primary Sjögren's syndrome. Further studies should be carried out in order to better understand pulmonary MALT lymphomagenesis, treatment, and outcomes in Sjögren's patients.

Keywords Lung neoplasms; Lymphoma B-cell; Non-Hodgkin's lymphoma; Sjögren's syndrome

$\mathrm{P}$ rimary Sjögren's syndrome (pSS) is a systemic autoimmune disease characterized by chronic lymphocytic infiltration of exocrine glands, leading to destruction of glandular tissue and an ensuing hypoproduction of saliva and tears. Among the autoimmune disorders, pSS is most strongly associated with the development of lymphoma. Eventually, $5 \%-10 \%$ of all patients with pSS develop a B-cell non-Hodgkin's lymphoma. ${ }^{1}$

Mucosa-associated lymphoid tissue (MALT) lymphomas, also known as extranodal marginal zone B-cell lymphoma (MZL) of MALT-type, are viewed as the most common histologic type in pSS. MALT lymphomas in patients with pSS are most frequently located in the parotid gland, although localization in other sites such as thyroid, stomach and lung has also been described. ${ }^{2-4}$
Extranodal MZL of the lung, sometimes referred to as bronchial-associated lymphoid tissue (BALT) lymphoma, is a rare pulmonary lymphoid malignancy. ${ }^{5,6}$ Occasionally, a preexisting autoimmune disorder, most notably pSS, is observed in patients with pulmonary MALT lymphomas. ${ }^{7}$ Uncertainties about clinical, radiologic, and pathologic aspects of pulmonary MALT lymphoma in patients with pSS remain. Herein, we describe all consecutive patients over a 16-year period who presented at our institution with pulmonary MALT lymphoma in the setting of underlying pSS.

\section{MATERIALS AND METHODS}

The study was approved by the Marshfield Clinic Institutional Review Board with waiver of the requirement to obtain written consent from subjects. We reviewed the medical records of all consecutive patients with biopsy-proven MZL of MALT-type of the lung who were evaluated at Marshfield

Received: September 4, 2016

Ist Revision: February 3, 2017

2nd Revision: April 13, 2017

Accepted: April 24, 2017
Department of Medicine, David Geffen School of Medicine, University of

California-Los Angeles, 10833 LeConte Avenue, Los Angeles, California 90095,

Phone: (310) 825-6373, Email: ryachoui@mednet.ucla.edu 
Table 1. Clinical characteristics of the seven patients included in the study.

\begin{tabular}{|c|c|c|c|c|c|c|}
\hline Case & $\begin{array}{l}\text { Age } \\
(y r s)^{a}\end{array}$ & Sex & pSS symptoms & $\begin{array}{l}\text { Lymphoma } \\
\text { symptoms }\end{array}$ & $\begin{array}{l}\text { Interval: } \\
\text { pSS to } \\
\text { lymphoma } \\
\text { (yrs) }^{\text {b }}\end{array}$ & $\begin{array}{l}\text { Smoking } \\
\text { status }\end{array}$ \\
\hline 1 & 71 & $\mathrm{~F}$ & $\begin{array}{l}\text { Sicca }{ }^{c} \text {, fatigue, myalgias, } \\
\text { arthralgias }\end{array}$ & None & 12 & Never \\
\hline 2 & 60 & $\mathrm{~F}$ & $\begin{array}{l}\text { Sicca, lung fibrosis, } \\
\text { arthralgias }\end{array}$ & $\begin{array}{l}\text { Dyspnea, } \\
\text { B-symptoms }^{d}\end{array}$ & 5 & Never \\
\hline 3 & 64 & $\mathrm{~F}$ & $\begin{array}{l}\text { Immune thrombocytopenia, } \\
\text { Raynaud's, Sicca, } \\
\text { arthralgias }\end{array}$ & Dyspnea, cough & 2 & Never \\
\hline 4 & 69 & $\mathrm{~F}$ & $\begin{array}{l}\text { Parotid enlargement, Sicca, } \\
\text { accelerated caries, } \\
\text { arthralgias }\end{array}$ & Dyspnea, cough & 3 & Current \\
\hline 5 & 68 & $\mathrm{~F}$ & Sicca, arthralgias & $\begin{array}{l}\text { Cough, B-symptoms, } \\
\text { hoarseness }\end{array}$ & 2 & Never \\
\hline 6 & 65 & M & Sicca, inflammatory arthritis & Cough & 15 & Former \\
\hline 7 & 65 & $\mathrm{~F}$ & $\begin{array}{l}\text { Xerostomia, Raynaud's, } \\
\text { myalgias }\end{array}$ & None & 13 & Former \\
\hline
\end{tabular}

aMean age at lymphoma diagnosis was 66 years.

${ }^{\mathrm{b}}$ Mean interval between onset of pSS and lymphoma was 7.4 years.

'Defined by the American-European Consensus Group and includes subjective and objective findings of ocular and/or oral dryness.

dDefined by Ann Arbor staging criteria and includes fever, weight loss, and night sweats.

Clinic, Marshfield, Wisconsin, from January 1, 1999, to December 31, 2015. Patients were identified from Marshfield Clinic's electronic medical record by billing codes for "MALT lymphoma of the lung" and "MZL of the lung". Only subjects with associated pSS according to the American-European Consensus Group criteria were further analyzed. ${ }^{8}$

Data were extracted using a standardized collection tool. Demographic data included age, sex, and ethnicity. Historical data included smoking history, presenting signs and symptoms at pSS and lymhoma diagnosis, and time from onset of pSS to diagnosis of lymphoma. Biological parameters included serological workup, complete blood count, erythrocyte sedimentation rate, and serum protein electrophoresis at the time of pSS diagnosis. Imaging included chest radiograph and thoracic computed tomography $(\mathrm{CT})$ at the time of cancer diagnosis. Histological data included method of biopsy (open lung biopsy or video-assisted thoracoscopic surgery), microscopic descriptions, and immunohistochemistry. Management and follow-up data included therapies utilized and outcome analysis. Data were analyzed using descriptive methods with means, medians, and proportions.

\section{RESULTS}

\section{Clinical Features and Laboratory Findings}

MZLs of MALT-type of the lung were diagnosed in 13 patients, seven of whom fulfilled the criteria for $\mathrm{pSS}^{8}{ }^{8} \mathrm{Six}$ patients had primary pSS, and one had secondary Sjögren's in association with rheumatoid arthritis. All patients were
Caucasian, and six were women. The mean age at cancer diagnosis was 66 years. The mean time elapsed from the onset of pSS to the development of lymphoma was 7.4 years. Sicca syndrome (keratoconjunctivitis sicca and/or xerostomia) was present in all patients with pSS. Other symptoms at diagnosis are summarized in Table 1. Slowly progressive dyspnea and dry cough were the most common presenting pulmonary symptoms of lymphoma; two individuals had additional B-symptoms, including fever, weight loss, and night sweats. A pulmonary lesion was incidentally noted on imaging in two asymptomatic patients.

All patients had positive antinuclear antibody and anti-SSA/ Ro antibody. Rheumatoid factor was positive in six cases. Most of the patients had elevated erythrocyte sedimentation rate. Lymphopenia was present in four patients. Cryoglobulin was not detected in the two patients who were tested. Hypocomplementemia was present in one of the two cases tested. A monoclonal gammopathy was present in three patients; the remaining four had polyclonal hypergammaglobulinemia.

\section{Imaging Findings}

Chest Roentgenograms

No unifying pattern was noted. In three patients, the chest roentgenogram was normal. In those cases, a chest CT was ordered either for symptoms or to confirm incidental findings on abdominal CT. One patient had increased interstitial markings suggestive of interstitial lung disease. A consolidative 


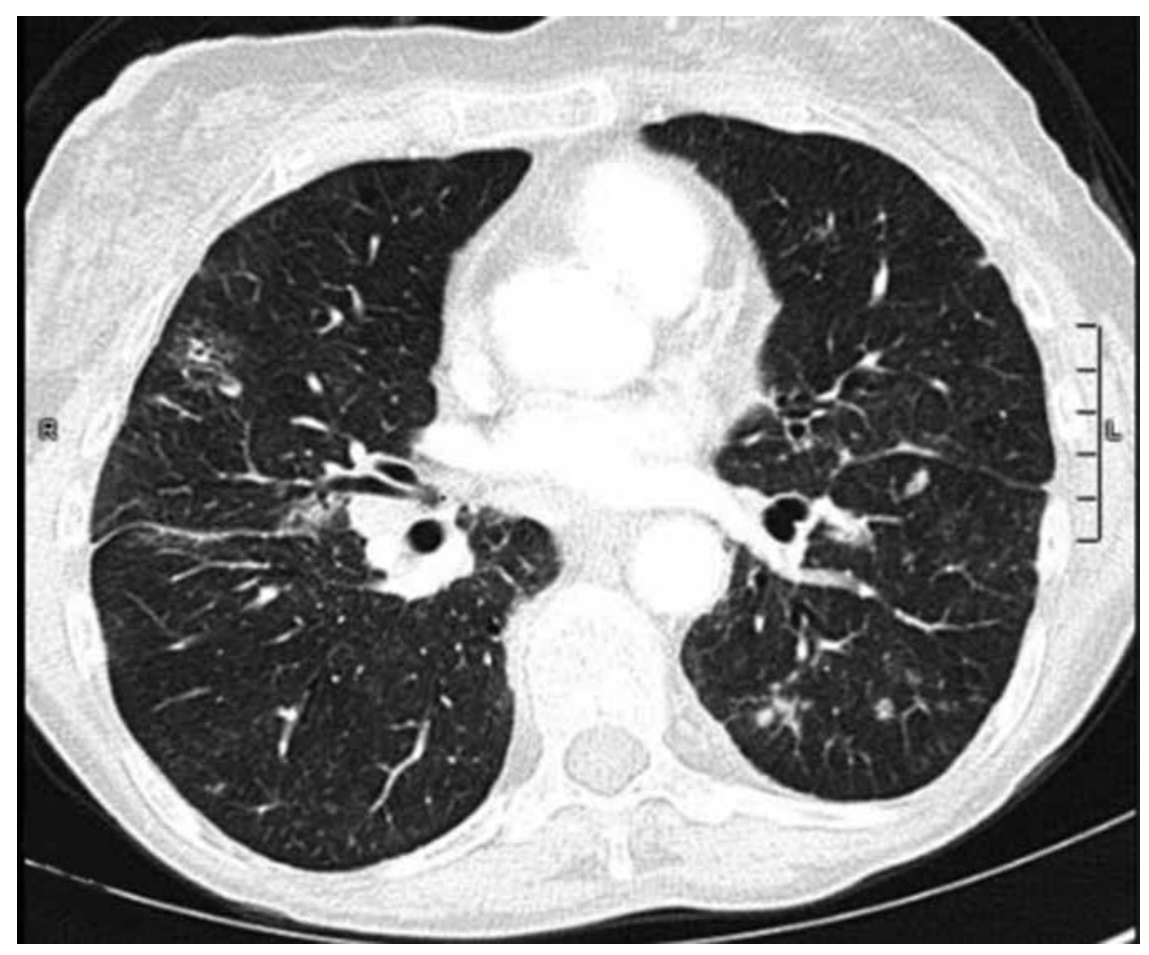

Figure 1. CT scan showing bilateral patchy ground glass opacities with solid nodular opacities.

pattern reflective of a pneumonitis was noted in two patients. Airway disease was found in two patients; one had hyperinflation, and one had bronchial wall thickening. Cavitations, pleural disease, and mediastinal adenopathy were never observed.

\section{Computed Tomography}

The CT appearance reflected the pattern of the disease on chest radiograph, when present, but also provided more details about the nature and distribution of the lesions and the structures involved. Airway disease (bronchial wall thickening and bronchiectasis) was found in five patients. The airway abnormalities were present bilaterally and mainly involved the lower lobes except in one patient where bronchiectasis was predominantly seen in the upper lobes. The lung parenchyma surrounding the abnormal airways was involved by confluent alveolar opacifications in two cases. In two other cases, there was a background of diffuse parenchymal ground glass changes (Figure 1). Another common finding observed in five patients was multiple nodular densities bilaterally, with ill-defined borders, ground glass texture, variable degrees of attenuation, and harboring a subtle pseudocavitation sign (Figure 2). The presence of masses was noted in two patients; one had multiple bilateral masses, and one had a single mass. Peripheral pneumonic infiltrates, some in a wedge shape pattern, were observed in four patients. Thin-walled cystic structures were identified in three patients (two of them were smokers). There were no pleural effusions noted. Subcentimetric mediastinal lymphadenopathy was seen in two patients but was not considered significant.

\section{Pathologic Descriptions}

Lung biopsy specimens were obtained by video-assisted thoracoscopic surgery in three patients and thoracotomy in the other four. In all seven specimens, infiltration of normal lung parenchyma by an infiltrate of lymphocytes including monocytoid forms and plasma cells was readily identified (Figure 3). Lymphoepithelial lesions involving the bronchial and bronchiolar epithelium were present in all cases (Figure 4). Other morphologic features of MALT lymphoma, including Dutcher bodies and colonization of residual lymphoid follicles by lymphoma cells, were variably present (Figure 5). CD20 stain was performed in all cases, with positive results. Co-expression of CD5, CD10, and cyclin D1 was absent whenever tested (four of seven cases for each marker). Kappa/lambda distribution was assessed in four cases (two by RNA in situ hybridization and two by immunohistochemistry): results were clonal in all cases (Figure 6). Proliferation was assessed by Ki-67 staining in two cases, and ranged from $5 \%$ to $50 \%$ proliferation fraction. Gene rearrangement studies were performed in four cases, with positive results in two cases, equivocal results in one case, and negative results in one case. Flow cytometry was only performed in one case, which showed a prominent CD38+ plasma cell population as well as a smaller B lymphocyte population with aberrant light chain intensity (inconclusive for kappa versus lambda specificity). One case contained squamous cell carcinoma in addition to the MALT lymphoma.

\section{Therapies and Outcomes}

Two patients were treated with surgery alone; both are currently disease-free at 3 and 5 years from initial diagnosis. 


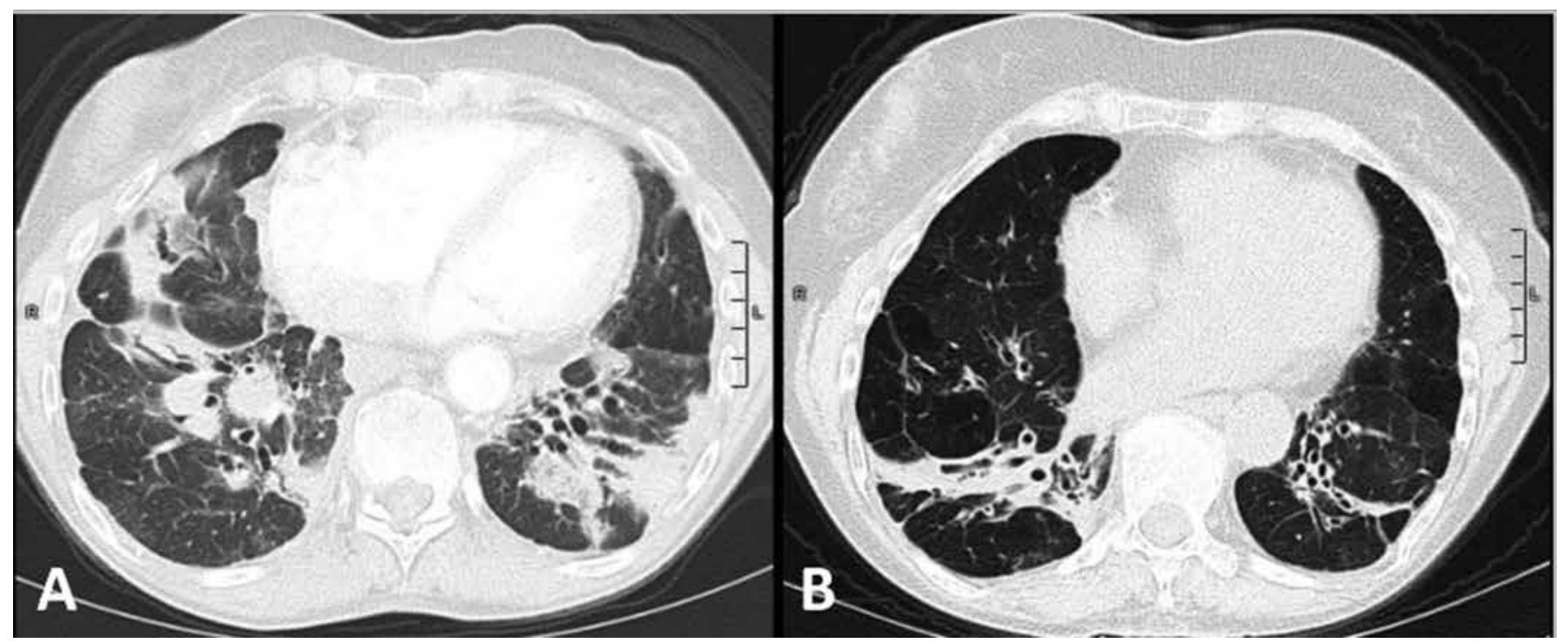

Figure 2. CT scans showing (A) nodular and peribronchovascular consolidation and $(B)$ resolved nodular consolidation after therapy. Mild progressive fibrosis is present.

One patient had surgical resection of a lung mass but had progression after 4.5 years, and was subsequently treated with single agent rituximab weekly for four doses and has not had progression/relapse for 3 years. One case was treated with watchful waiting and remains disease-free to date. Another case was also observed initially, but then progressed 2 years later. The patient was treated first with single agent rituximab weekly for four doses with further progression of disease. Subsequently, the patient responded to bendamustine and rituximab and has not had progression/relapse for 5 years. Another patient with advanced lymphoma was treated with chemotherapy alone (R-CVP regimen [rituximab, cyclophosphamide, vincristine, and prednisone] for six cycles) with complete remission and without progression/relapse for 5 years. One patient diagnosed prior to the CD20 targeted therapy era was treated with long-term antibiotic therapy with tetracycline with complete radiographic and clinical response. The patient died 11 years later with no lymphoma but of another cause. All remaining six patients are still alive and disease-free to date.

\section{DISCUSSION}

We present a large series of pulmonary MALT lymphoma in pSS. The involvement of the lungs by MALT lymphoma in patients with pSS has been reported only briefly in the literature. ${ }^{9}, 10$ According to the latest World Health Organization (WHO) lymphoma classification scheme, MALT lymphomas are considered a subtype of B-cell marginal zone lymphoma (MZL). ${ }^{11}$ The presence of MALT in the lung was first described by Bienenstock and colleagues in 1973 as peribronchiolar lymphoid aggregates bearing a close similarity to Peyer's patches. ${ }^{12}$ Certain conditions, such as chronic lung infections, smoking history, and autoimmune diseases notably pSS have been shown to trigger the formation of MALT in the lungs, which can further transform to lymphoid malignancy. ${ }^{13}$
MZLs of MALT-type of the lung have been associated with underlying Helicobacter pylori infection, human immunodeficiency virus infection, common variable immunodeficiency, chronic hepatitis $\mathrm{C}$, and Borrelia burgdorferi infection, as well as autoimmune diseases. ${ }^{9}$ In our series, out of 13 patients with pulmonary MALT lymphoma, 7 (54 \%) met the criteria for Sjögren's syndrome. Similar to previous published reports, ${ }^{7,14}$ the mean age at lymphoma diagnosis in this study was 66 years. The youngest patient was aged 60 years, and the oldest was aged 71 years. Female patients predominated in this and in most other reported studies ${ }^{7,9}$ with a male to female ratio of 1:6. All patients in this series were Caucasian. In the current study, one-third of patients were asymptomatic at the time that lymphoma was discovered. When symptomatic, patients generally reported nonspecific pulmonary complaints such as cough and dyspnea, and some experienced fever, night sweats, and weight loss. Sicca and arthralgias were the most common presenting symptoms of pSS, and the mean time interval from onset of pSS to establishment of lymphoma diagnosis in our study was 7.4 years.

The morphologic, immunohistochemical, and molecular features of pSS-associated pulmonary MALT lymphomas do not differ significantly from pulmonary MALT lymphoma cases in general. ${ }^{7}$ Pseudolymphoma has been described in pSS, but can be distinguished from pulmonary MALT lymphoma on the basis of lymphocyte clonality, extent of involvement, and other neoplastic features such as Dutcher bodies. In the present series, all pathological reports showed lymphoepithelial lesions containing dense proliferations of B-cells. The neoplastic cells were morphologically described as monocytoid-like in almost all cases, and large cells were absent. The overall imaging features are in accordance with previously published series of pulmonary MALT lymphoma both associated and not associated with pSS. ${ }^{10}$ 
Some of the well-known predictors of lymphomagenesis in pSS that are easily checked in daily practice include permanent swelling of salivary glands, lymphadenopathies, palpable purpura, cryoglobulinemia, lymphopenia, low complement levels, and a monoclonal component in serum or urine. ${ }^{15}$ In the cases we present, lymphopenia was present in four patients, and a monoclonal gammopathy was present in three patients. In pSS, circulating immunoglobulin $\mathrm{M}$ autoantibodies that are specific for immunoglobulin G-Fc, called rheumatoid factors (RFs), are found in the serum of $50 \%-60 \%$ of affected individuals. ${ }^{16}$ In addition to previously known predictive factors of lymphoma occurrence, Nocturne and colleagues ${ }^{17}$ recently demonstrated the independent role of $\mathrm{RF}$ in the development of this severe complication. In our series, out of seven patients, six tested positive for RF. This observation further supports the role of RF as a risk factor for the occurrence of subsequent pulmonary MALT lymphoma in patients with pSS.

Bende et $\mathrm{al}^{18}$ analyzed the structure of antigen receptors of a comprehensive panel of mature B-cell non-Hodgkin's lymphomas by comparing, at the amino acid level, their immunoglobulin VH-CDR3s with CDR3 sequences present in GenBank. They found that among B-cell non-Hodgkin's lymphomas, MALT lymphomas express a unique antibody repertoire with frequent RF reactivity. ${ }^{18}$ Thus, RF+ B-cells in the MALT tissue are thought to be more prone to transform into malignant lymphoma cells. In pSS patients, the chronic stimulation by immune complexes (with Ro/La or an unknown auto-antigen) of polyclonal marginal zone $\mathrm{RF}+\mathrm{B}$-cells might precipitate their monoclonal lymphomatous escape and would be a key event involved in lymphomagenesis. ${ }^{15}$ Therefore, negativation of RF could be an important target for new treatments, particularly regarding the possible decreased risk of subsequent lymphoma in pSS patients.

Two previous large retrospectives studies did not show different outcomes between patients receiving different treatment modalities, i.e. surgery, chemotherapy or combined therapy. ${ }^{19,20}$ Watchful waiting, without specific treatment, is reserved for asymptomatic cases. Treatment is indicated for patients with bulky lymphadenopathies and/or splenomegaly, risk of local compressive disease resulting in organ dysfunction, significant cytopenias from bone marrow compromise, and/or

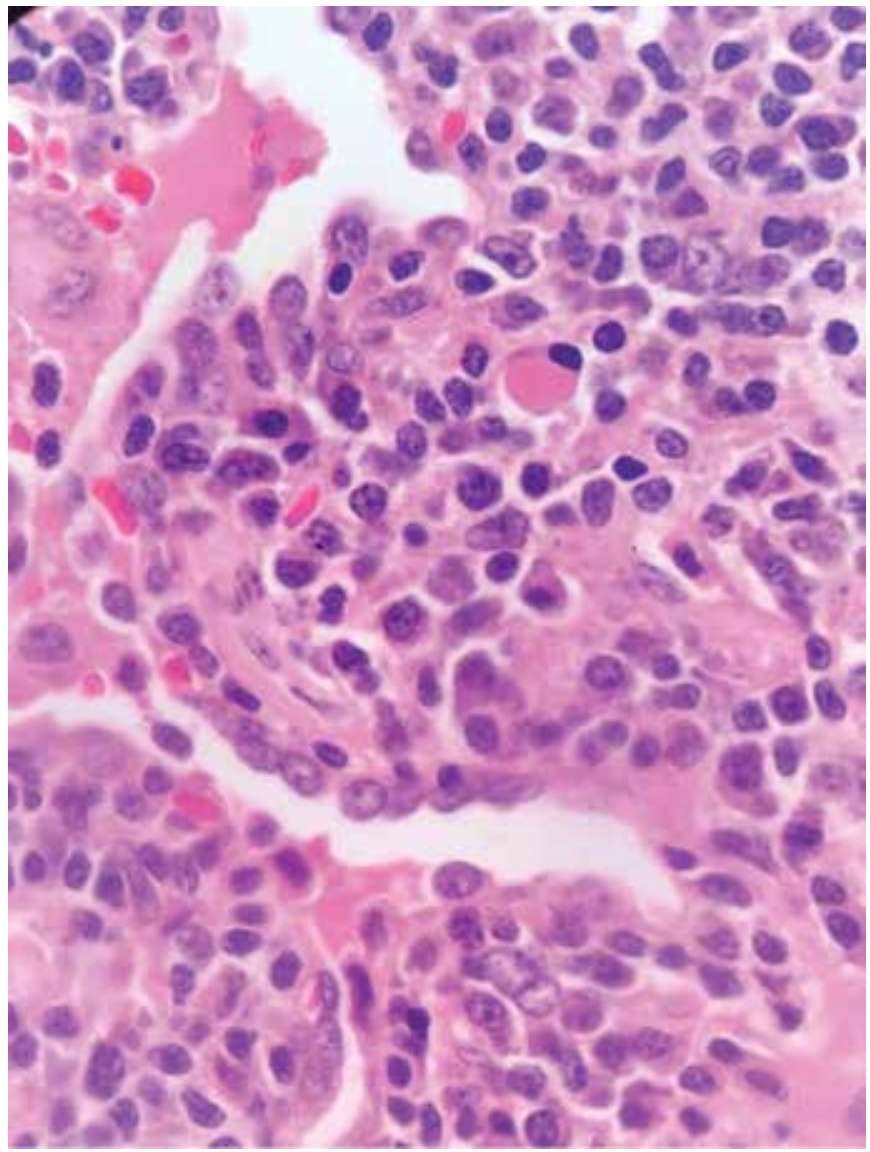

Figure 3. H\&E features of MALT lymphoma include effacement of normal pulmonary structures by an infiltrate of lymphocytes and plasma cells. Lymphocytes include small monocytoid forms and occasional larger forms. Destruction of lung parenchyma is evident.

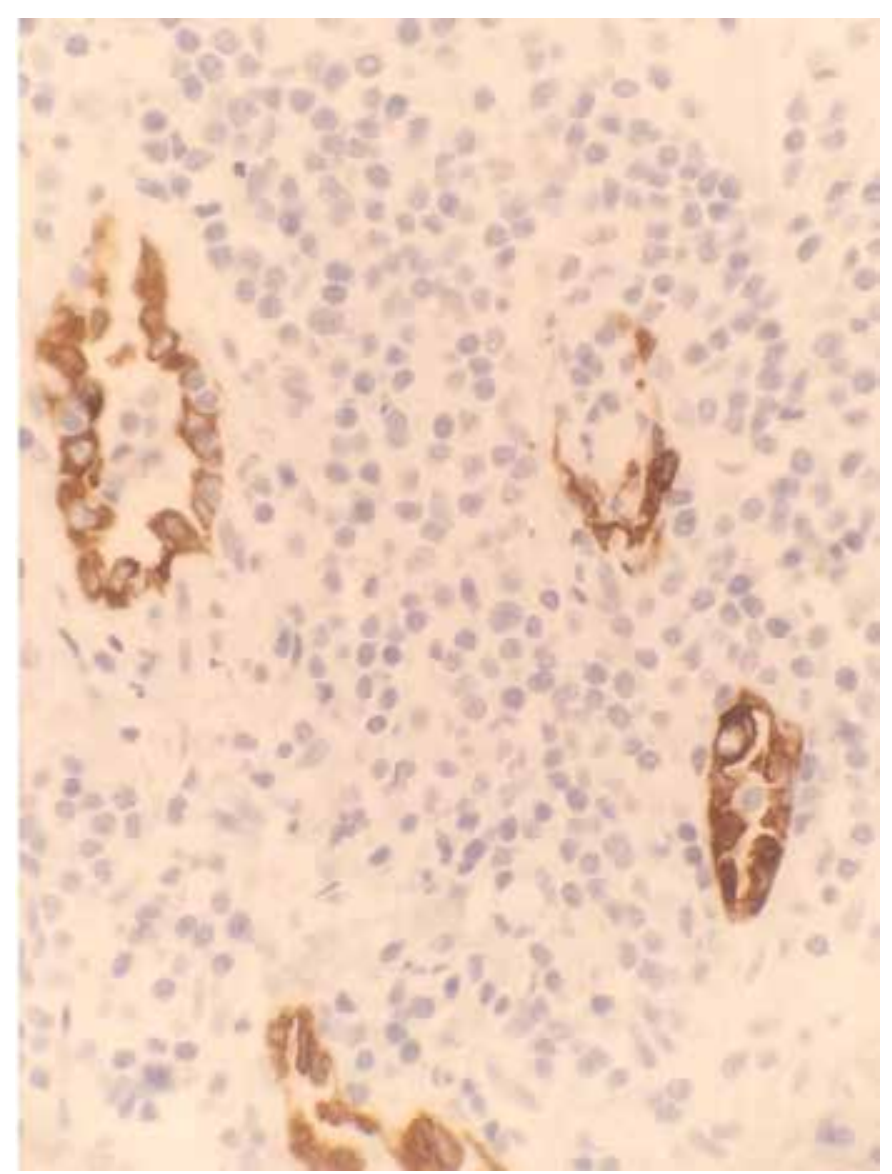

Figure 4. Cytokeratin stain (brown) highlights destruction of native epithelial structures by the B-cells of MALT Iymphoma (nuclei counterstained in blue). 

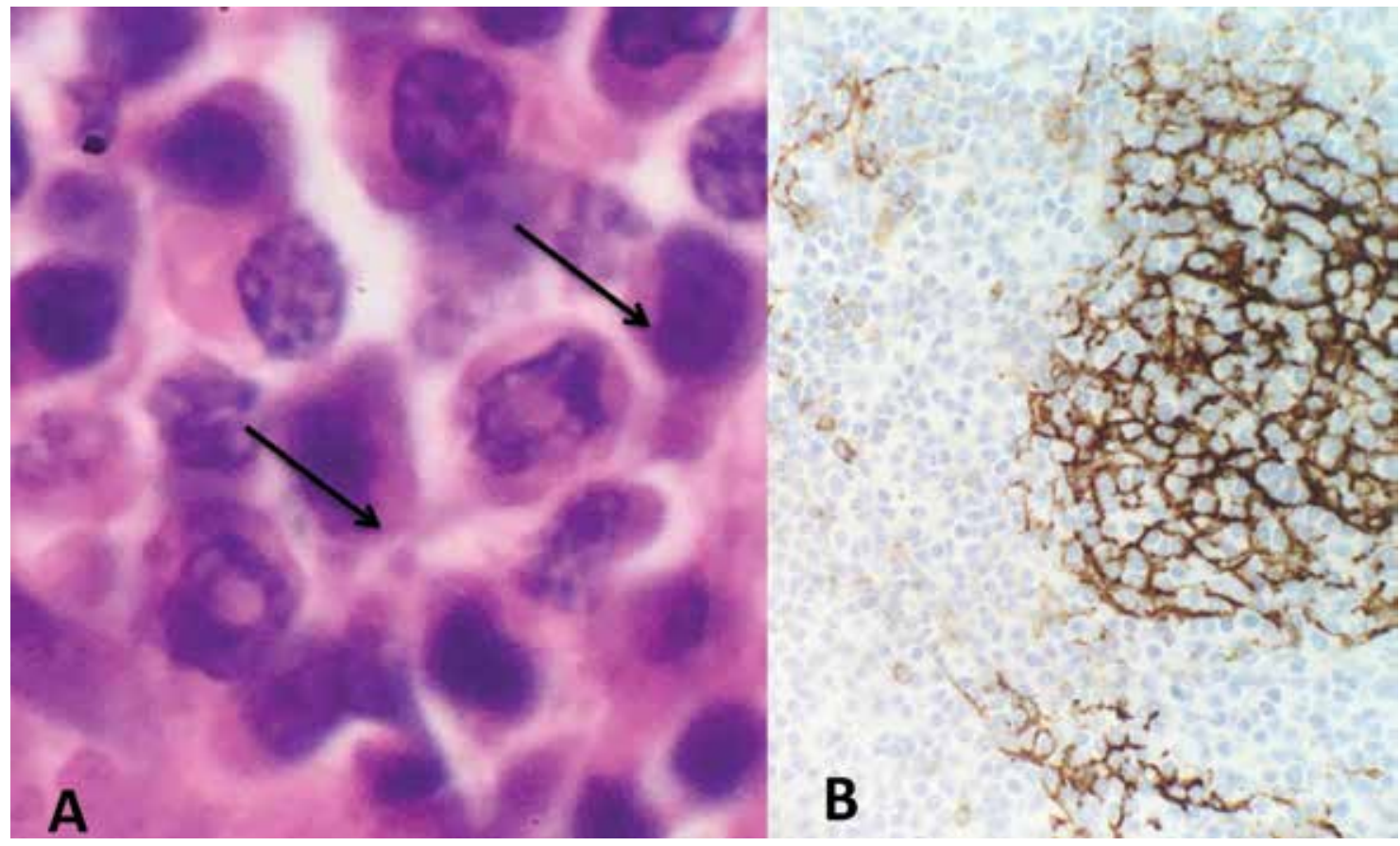

Figure 5. (A) Arrows indicate two Dutcher bodies (pseudonuclear immunoglobulin inclusions characteristic of marginal zone lymphoma). CD23 stain (B) highlights residual follicular dendritic meshwork (brown) in a germinal center colonized by MALT lymphoma cells (nuclei counterstained in blue).

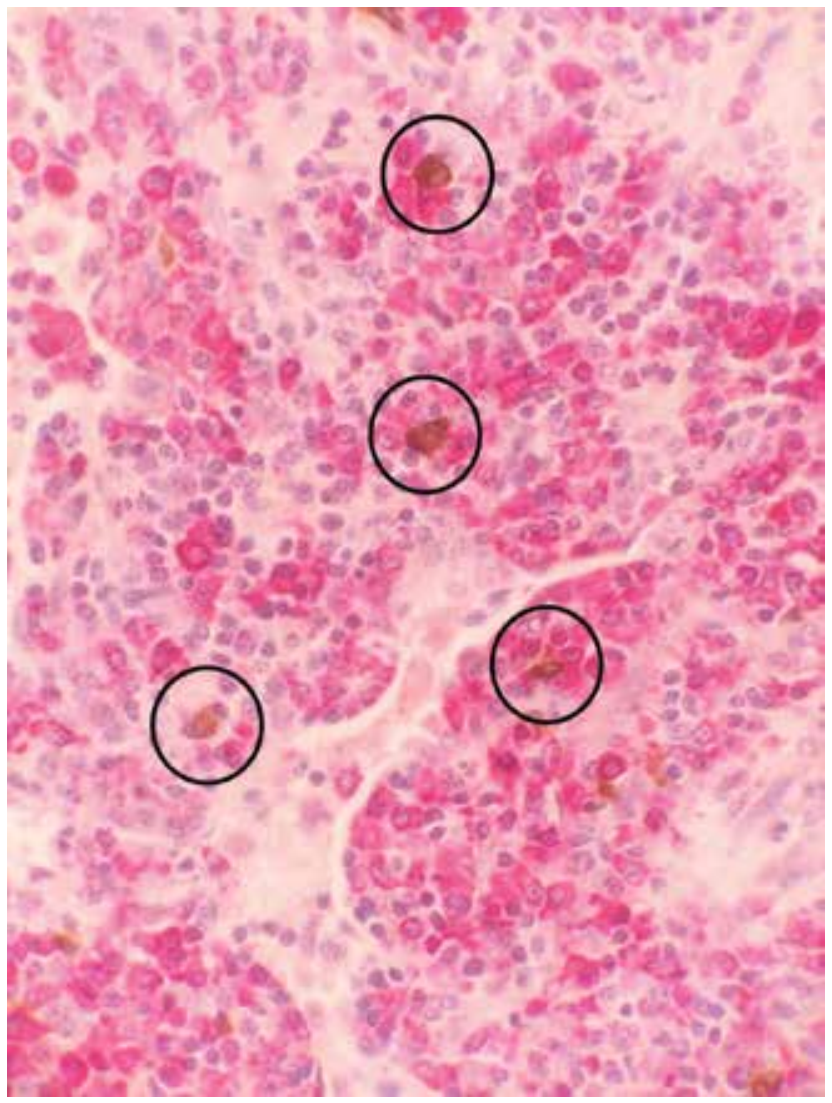

Figure 6. Dual stained RNA in situ hybridization reveals pronounced excess of kappa light chain staining (red) over lambda light chain staining (brown, circled), indicating clonal expansion of plasma cells. rapid disease progression. ${ }^{21}$ The present series confirms the favorable course of pulmonary MALT lymphoma with all treatment modalities resulting in complete and sustained response. ${ }^{22}$ Further multicenter prospective studies should be carried out in order to better understand pulmonary MALT lymphomagenesis, treatment, and outcomes in pSS patients.

\section{REFERENCES}

1. Zintzaras E, Voulgarelis M, Moutsopoulos HM. The risk of lymphoma development in autoimmune diseases: a metaanalysis. Arch Intern Med 2005; 165:2337-2344.

2. Papageorgiou A, Ziogas DC, Mavragani CP, Zintzaras E, Tzioufas AG, Moutsopoulos HM, Voulgarelis M. Predicting the outcome of Sjogren's syndrome-associated non-hodgkin's lymphoma patients. PLoS One 2015; 10:e0116189.

3. Royer B, Cazals-Hatem D, Sibilia J, Agbalika F, Cayuela JM, Soussi T, Maloisel F, Clauvel JP, Brouet JC, Mariette X. Lymphomas in patients with Sjogren's syndrome are marginal zone B-cell neoplasms, arise in diverse extranodal and nodal sites, and are not associated with viruses. Blood 1997; 90:766-775.

4. Ekstrom Smedby K, Vajdic CM, Falster M, Engels EA, MartinezMaza O, Turner J, Hjalgrim H, Vineis P, Seniori Costantini A, et al. Autoimmune disorders and risk of non-Hodgkin lymphoma subtypes: a pooled analysis within the InterLymph Consortium. Blood 2008; 111:4029-4038.

5. Sirajuddin A, Raparia K, Lewis VA, Franks TJ, Dhand S, Galvin JR, White CS. Primary Pulmonary Lymphoid Lesions: Radiologic and Pathologic Findings. Radiographics 2016; 36:53-70.

6. Zinzani PL, Tani M, Gabriele A, Poletti V, Stefoni V, Alinari L, Musuraca G, Bonifazi F, Pileri S, Tura S, Baccarani M. Extranodal Marginal Zone B-cell lymphoma of MALT-type of the lung: single center experience with 12 patients. Leuk Lymphoma 2003; 44:821-824. 
7. Kurtin PJ, Myers JL, Adlakha H, Strickler JG, Lohse C, Pankratz VS, Inwards DJ. Pathologic and clinical features of primary pulmonary extranodal Marginal Zone B cell lymphoma of MALT type. Am J Surg Pathol 2001; 25:997-1008.

8. Vitali C, Bombardieri S, Jonsson R, Moutsopoulos HM, Alexander EL, Carsons SE, Daniels TE, Fox PC, Fox RI, Kassan SS, Pillemer SR, Talal N, Weisman MH; European Study Group on Classification. Criteria for Sjögren's Syndrome Classification criteria for Sjogren's syndrome: a revised version of the European criteria proposed by the American-European Consensus Group. Ann Rheum Dis 2002; 61:554-558.

9. Papiris SA, Kalomenidis I, Malagari K, Kapotsis GE, Harhalakis N, Manali ED, Rontogianni D, Roussos C, Moutsopoulos HM. Extranodal marginal zone B-cell lymphoma of the lung in Sjögren's syndrome patients: reappraisal of clinical, radiological, and pathology findings. Respir Med 2007; 101:84-92.

10. Hansen LA, Prakash UB, Colby TV. Pulmonary lymphoma in Sjogren's syndrome. Mayo Clin Proc 1989; 64:920-31.

11. Swerdlow SH, Campo E, Harris NL, Jaffe ES, Pileri SA, Stein H, Thiele J, Vardiman JW, eds. WHO Classification of Tumours of Haematopoietic and Lymphoid Tissues. In: WHO Classification of Tumours. Vol 2. 4th ed. Lyon, France: IARC Press; 2008.

12. Bienenstock J, Johnston N, Perey DY. Bronchial lymphoid tissue. I. Morphologic characteristics. Lab Invest 1973; 28:686-692.

13. Pabst R. Is BALT a major component of the human lung immune system? Immunol Today 1992; 13:119 122.

14. Zinzani PL, Tani M, Gabriele A, Poletti V, Stefoni V, Alinari L, Musuraca G, Bonifazi F, Pileri S, Tura S, Baccarani M. Extranodal marginal zone B-cell lymphoma of MALT-type of the lung: single-center experience with 12 patients. Leuk Lymphoma 2003; 44:821-824.

15. Nocturne G, Mariette X. Sjögren Syndrome-associated lymphomas: an update on pathogenesis and management. $\mathrm{Br} \mathrm{J}$ Haematol 2015; 168:317-327.

16. Atkinson JC, Fox PC, Travis WD, Popek E, Katz RW, Balow JE, Pilemer SR. IgA rheumatoid factor and IgA containing immune complexes in primary Sjögren's syndrome. J Rheumatol 1989; 16:1205-1210.

17. Nocturne G, Virone A, Ng WF, Le Guern V, Hachulla E, Cornec D, Daien C, Vittecoq O, Bienvenu B, Marcelli C, Wendling D, Amoura Z, Dhote R, Lavigne C, Fior R, Gottenberg JE, Seror R, Mariette X. Rheumatoid factor and disease activity are independent predictors of lymphoma in primary Sjögren's Syndrome. Arthritis Rheumatol 2016; 68:977-985.

18. Bende RJ, Aarts WM, Riedl RG, de Jong D, Pals ST, van Noesel CJ. Among B cell non-Hodgkin's lymphomas, MALT lymphomas express a unique antibody repertoire with frequent rheumatoid factor reactivity. J Exp Med 2005; 201:1229-1241.

19. Pinotti G, Zucca E, Roggero E, Pascarella A, Bertoni F, Savio A, Savio E, Capella C, Pedrinis E, Saletti P, Morandi E, Santandrea G, Cavalli F. Clinical features, treatment and outcome in a series of 93 patients with low-grade gastric MALT lymphoma. Leuk Lymphoma 1997; 26:527-537.

20. Thieblemont C, Dumontet C, Bouafia F, Hequet O, Arnaud P, Espinouse D, Felman P, Berger F, Salles G, Coiffier B. Outcome in relation to treatment modalities in 48 patients with localized gastric MALT lymphoma: a retrospective study of patients treated during 1976-2001. Leuk Lymphoma 2003; 44:257-262.

21. Gribben JG. How I treat indolent lymphoma. Blood 2007; 109:4617-4626.
22. Borie R, Wislez M, Thabut G, Antoine M, Rabbat A, Couderc LJ, Monnet I, Nunes H, Blanc FX, Mal H, Bergeron A, Dusser D, Israël-Biet D, Crestani B, Cadranel J. Clinical characteristics and prognostic factors of pulmonary MALT lymphoma. Eur Respir J 2009; 34:1408-1416.

\section{AUTHOR AFFILIATIONS}

Ralph Yachoui, MD*; Chady Leon, MD广; Kajal Sitwala, MD $\neq$ and Mazen Kreidy, MDई

*Department of Rheumatology, Marshfield Clinic, Marshfield, Wisconsin USA; Current affiliation: Division of Rheumatology, Department of Medicine, David Geffen School of Medicine, University of California-Los Angeles, Los Angeles, California, USA

†Department of Oncology/Hematology, Marshfield Clinic, Marshfield, Wisconsin USA

$\neq$ Department of Lab/Pathology, Marshfield Clinic,

Marshfield, Wisconsin USA

$\S$ Department of Pulmonary Medicine, Marshfield Clinic, Marshfield, Wisconsin USA 